\title{
TRATAMENTOS PRÉ-GERMINATIVOS E TEMPERATURAS PARA A GERMINAÇÃO DE SEMENTES DE Apeiba tibourbou Aubl. ${ }^{1}$
}

\author{
ROBERTA SALES GUEDES ${ }^{2}$, EDNA URSULINO ALVES ${ }^{3}$, JEANDSON SILVA VIANA ${ }^{4}$, \\ EDILMA PEREIRA GONÇALVES ${ }^{4}$, SEVERINO DO RAMO NASCIMENTO DOS SANTOS ${ }^{5}$, EDILSON GUEDES DA COSTA ${ }^{6}$.
}

\begin{abstract}
RESUMO - A Apeiba tibourbou Aubl. é uma espécie arbórea pertencente à família Tiliaceae, conhecida popularmente como pau-de-jangada, sendo utilizada como planta ornamental, na medicina popular e na fabricação de pequenas embarcações. Objetivou-se nesse trabalho avaliar o efeito de diferentes tratamentos pré-germinativos e de temperaturas na germinação de sementes de A. tibourbou. As sementes foram submetidas aos seguintes tratamentos: testemunha - sementes intactas $\left(\mathrm{T}_{1}\right)$; escarificação mecânica com lixa d'água no 80 , por 5 minutos $\left(\mathrm{T}_{2}\right)$; escarificação mecânica com lixa d'água no 80 , por 5 minutos, seguida de embebição em água à temperatura ambiente por 12 e $24 \mathrm{~h}\left(\mathrm{~T}_{3}\right.$ e $\mathrm{T}_{4}$, respectivamente); imersão em água na temperatura de $100{ }^{\circ} \mathrm{C}$ por 15 minutos $\left(\mathrm{T}_{5}\right)$ e imersão em ácido sulfúrico por $1,5,10,15$ e 20 minutos $\left(\mathrm{T}_{5}, \mathrm{~T}_{6}, \mathrm{~T}_{7}, \mathrm{~T}_{8}\right.$, $\mathrm{T}_{9}$ e $\mathrm{T}_{10}$, respectivamente) e colocadas para germinar nas temperaturas de $25,30,35$ e $20-30{ }^{\circ} \mathrm{C}$. Utilizou-se o delineamento inteiramente ao acaso, com quatro repetições, sendo os tratamentos distribuídos em esquema fatorial 10 x 4 e as médias comparadas pelo teste de Scott - Knott, a $5 \%$ de probabilidade. As características avaliadas foram: porcentagem de germinação, primeira contagem de germinação, índice de velocidade de germinação e comprimento de plântulas. Os tratamentos que envolveram a imersão em ácido sulfúrico não superaram a dormência de sementes de $A$. tibourbou. Para germinação das sementes de A. tibourbou recomenda-se a escarificação com lixa d'água no 80 por 5 minutos e a temperatura de $30^{\circ} \mathrm{C}$.
\end{abstract}

Termos para indexação: pau-de-jangada, dormência, sementes florestais.

\author{
PRE-GERMINATION TREATMENTS AND TEMPERATURES FOR \\ GERMINATION OF Apeiba tibourbou Aubl. SEEDS
}

\begin{abstract}
Apeiba tibourbou Aubl. is a forest species belonging to the family Tiliaceae, used as an ornamental, a medicine and for building small boats. The objective in this study was to evaluate the effect of different pre-germination treatments and temperatures on the germination of A. tibourbou seeds. The seeds were submitted to the following treatments: control - intact seeds $\left(\mathrm{T}_{1}\right)$; mechanical scarification with sandpaper number 80 for 5 minutes $\left(\mathrm{T}_{2}\right)$; mechanical scarification with sandpaper number 80 for 5 minutes, followed by immersion in water at room
\end{abstract}

${ }^{1}$ Submetido em 11/11/2009. Aceito para publicação em 26/10/2010.

${ }^{2}$ Bióloga, MSc. doutoranda em Agronomia, Centro de Ciências Agrárias, Universidade Federal da Paraíba (CCA - UFPB); e-mail: roberta_biologa09@yahoo.com.br,

${ }^{3}$ Eng. Agr., Dra., Profa. Titular, Depto. de Fitotecnia, CCA - UFPB, Caixa postal 02, 58397-000,Areia-PB; ednaursulino@cca.ufpb.br
${ }^{4}$ Eng. Agr., Drs., Profs. Titulares, Unidade Acadêmica de Garanhuns, UAG - UFRPE, Av. Bom Pastor, SN, Boa Vista, 55296-901, Garanhuns - PE; edilmapg@hotmail.com

${ }^{5}$ Eng. Agr., mestrando em Agronomia, Centro de Ciências Agrárias, Universidade Federal da Paraíba (CCA - UFPB); ninoagro@hotmail.com

${ }^{6}$ Eng. Agr., Depto. de Fitotecnia, CCA - UFPB; didiuguedes@yahoo.com.br 
temperature for 12 and 24 hours $\left(\mathrm{T}_{3}\right.$ and $\mathrm{T}_{4}$, respectively); immersion in sulphuric acid for $1,5,10$, 15 and 20 minutes $\left(\mathrm{T}_{5}, \mathrm{~T}_{6}, \mathrm{~T}_{7}, \mathrm{~T}_{8}, \mathrm{~T}_{9}\right.$ and $\mathrm{T}_{10}$, respectively) and incubated at 25, 30, 35 and 20-30

${ }^{\circ} \mathrm{C}$. The experimental design was completely randomized with four replications and the treatments were arranged in $10 \times 4$ factorial. The means were compared using the Scott-Knott test, at the $5 \%$ probability level. Evaluations made were: percentage germination, first count germination, germination speed index and seedling length. The treatments with sulphuric acid immersion did not break the dormancy of $A$. tibourbou seeds. For the germination test with $A$. tibourbou seeds, the scarification in water with sandpaper number 80 for 5 minutes and a temperature of $30{ }^{\circ} \mathrm{C}$ is recommended.

Index terms: pau-de-jangada, dormancy, forest seeds.

\section{INTRODUÇÃO}

Apeiba tibourbou Aubl., conhecida popularmente como pau-de-jangada, pente-de-macaco, embira-branca ou jangadeira, é uma espécie arbórea pertencente à família Tiliaceae, que ocorre desde o Norte do Brasil até Minas Gerais e São Paulo. Sua madeira, devido à baixa densidade é empregada na fabricação de pequenas embarcações; suas folhas e frutos decorativos potencializam o uso dessa árvore no paisagismo, podendo também ser usada na recuperação de áreas degradadas, por ser uma planta pioneira e de rápido crescimento (Lorenzi, 2002). Além disso, a casca serve de matéria-prima para a confecção de cordas.

Para muitas espécies é bastante comum encontrar sementes que, embora permanecendo viáveis por longos períodos no banco de sementes do solo, a germinação é lenta e irregular, mesmo quando expostas a condições ambientais favoráveis (Murdoch e Ellis, 2000). Esse fenômeno é denominado dormência e consiste em estratégia natural de sobrevivência da semente no solo, após maturação e dispersão, para garantir a perpetuação da espécie (Piña-Rodrigues e Aguiar, 1993). Neste caso, o conhecimento de suas causas é de importância prática, visto que permite a aplicação de tratamentos apropriados para se obter melhor germinação (Melo et al., 1998).

A dormência das sementes pode ser devida a fatores como impermeabilidade do tegumento à água e aos gases, embriões fisiologicamente imaturos ou rudimentares, presença de substâncias promotoras ou inibidoras de crescimento, embrião dormente, exigências especiais de luz ou de temperatura, entre outras (Carvalho e Nakagawa, 2000). Entre os métodos empregados para superação da dormência, a escarificação mecânica é uma técnica frequentemente utilizada e constitui uma opção prática, de baixo custo e eficaz para promover uma germinação rápida e uniforme (Hermansen et al., 2000). No entanto, deve ser efetuada com muito cuidado para evitar que a escarificação excessiva atinja os tecidos da semente e diminua a germinação (McDonald e Copeland, 1997).

A escarificação mecânica do tegumento foi eficiente na superação da dormência de sementes de várias espécies com tegumento impermeável, como as sementes de Bowdichia virgilioides Kunth (Smiderle e Sousa, 2003), Bauhinia divaricata L. (Alves et al., 2004), Peltophorum dubium (Spreng.) Taub. (Piroli et al., 2005), Trifolium riograndense Burkart e Desmanthus depressus Humb (Suñé e Franke, 2006), Erythrina velutina Willd. (Silva et al., 2007) e de Caesalpinia pucherrima (L.) Sw. (Oliveira et al., 2010).

A escarificação química com ácidos é amplamente usada, mas deve ser aplicada com certo cuidado, uma vez que longos períodos de exposição causam danos às sementes e, consequentemente, redução na germinação (Egley, 1972). A escarificação com ácidos foi empregada com eficiência na superação da dormência de sementes de Bowdichia virgilioides Kunth (Smiderle e Sousa, 2003), Zizyphus joazeiro Mart. (Alves et al., 2006), Merremia aegyptia L. (Pereira et al., 2007), Acacia mangium Willd. (Rodrigues et al., 2008) e Merremia cissoides (Lam.) Hall. F. (Sousa et al., 2010).

A ruptura do tegumento pelos métodos de escarificação, além de aumentar a permeabilidade à água, pode induzir a um aumento da sensibilidade à luz e temperatura, da permeabilidade aos gases, da remoção de inibidores e promotores e da possibilidade de injúrias aos tecidos (Jeller e Perez, 1999). Todas essas alterações possuem significante influência no metabolismo das 
sementes e, conseqüentemente, na dormência (Khan, 1977; Mayer e Poljakoff- Mayber, 1989). Entretanto, a aplicação e eficácia desses tratamentos dependem da causa e do grau de dormência, o que é bastante variável entre as espécies (Lima e Garcia, 1996).

Outro fator ambiental que pode interferir na capacidade germinativa de sementes das espécies é a temperatura, cujos efeitos também podem ser avaliados a partir de mudanças ocasionadas na porcentagem e velocidade de germinação (Fonseca e Perez, 1999), pois a germinação ocorre em limites bem definidos de temperatura, dentro dos quais existe uma temperatura em que o processo ocorre com maior eficiência (Carvalho e Nakagawa, 2000). Esta temperatura que otimiza o processo germinativo é variável entre as diferentes espécies, estando relacionada à distribuição geográfica das mesmas. Conforme Marcos Filho (2005) as variações de temperatura afetam a velocidade, a percentagem e a uniformidade de germinação, sendo considerada como ótima a temperatura que possibilita a combinação mais eficiente entre a porcentagem e a velocidade de germinação.

Devido à dormência causada pela impermeabilidade do tegumento à água considerável número de sementes de Apeiba tibourbou Aubl. pode permanecer sem germinar, durante os testes de germinação ou em sementeiras destinadas à formação de mudas. Objetivou-se nesse trabalho avaliar o efeito de diferentes tratamentos prégerminativos e temperaturas na germinação de sementes de Apeiba tibourbou.

\section{MATERIAL E MÉTODOS}

A pesquisa foi conduzida no Laboratório de Análise de Sementes (LAS), do Centro de Ciências Agrárias, da Universidade Federal da Paraíba, (CCA - UFPB), em Areia - PB. Os frutos de Apeiba tibourbou Aubl. foram coletados diretamente de cinco árvores matrizes, no CCA - UFPB, os quais foram levados ao LAS para extração manual das sementes. Depois de beneficiadas as sementes foram submetidas aos tratamentos contidos na Tabela 1 .

TABELA 1. Tratamentos pré-germinativos aplicados para superação da dormência de sementes de Apeiba tibourbou Aubl.

\section{Descrição dos tratamentos pré-germinativos}

\begin{tabular}{ll}
\hline $\mathrm{T}_{1}$ & Testemunha - sementes intactas \\
$\mathrm{T}_{2}$ & Escarificação mecânica com lixa d'água $\mathrm{n}^{\mathrm{o}} 80$ por 5 minutos \\
$\mathrm{T}_{3}$ & Escarificação mecânica com lixa d'água $\mathrm{n}^{\mathrm{o}} 80$, seguida de embebição em água por $12 \mathrm{~h}$ \\
$\mathrm{~T}_{4}$ & Escarificação mecânica com lixa d'água $\mathrm{n}^{\mathrm{o}} 80$, seguida de embebição em água por $24 \mathrm{~h}$ \\
$\mathrm{~T}_{5}$ & Imersão em água na temperatura de $100^{\circ} \mathrm{C}$ por 15 minutos \\
$\mathrm{T}_{6}$ & Imersão em ácido sulfúrico por 1 minutos \\
$\mathrm{T}_{7}$ & Imersão em ácido sulfúrico por 5 minutos \\
$\mathrm{T}_{8}$ & Imersão em ácido sulfúrico por 10 minutos \\
$\mathrm{T}_{9}$ & Imersão em ácido sulfúrico por 15 minutos \\
$\mathrm{T}_{10}$ & Imersão em ácido sulfúrico por 20 minutos \\
\hline
\end{tabular}

A testemunha correspondeu às sementes que foram colocadas diretamente para germinar, sem qualquer tratamento. A escarificação mecânica foi realizada através de fricção das sementes entre duas lixas $n^{\circ} 80$ por 5 minutos, realizando-se movimentos circulares, a fim de escarificar uniformemente as sementes. $\mathrm{Na}$ imersão em ácido sulfúrico as sementes foram colocadas em Becker e constantemente revolvidas com um bastão de vidro, objetivando uniformizar a ação abrasiva do ácido. Decorridos os períodos pré-estabelecidos, as sementes foram lavadas em água corrente, por 10 minutos, para que os resíduos do ácido fossem totalmente retirados.

Após a aplicação dos tratamentos pré-germinativos as sementes foram submetidas ao teste de germinação. Para tanto foram utilizadas 100 sementes por tratamento, divididas em quatro repetições de 25 unidades, as quais foram distribuídas sobre duas folhas de papel toalha e cobertas com uma terceira folha, e organizados em forma de rolo, sendo que o mesmo foi umedecido com água destilada no volume $(\mathrm{mL})$ equivalente a 2,5 vezes a massa 
do papel não hidratado, sem adição posterior de água.

Após a distribuição das sementes, os rolos foram levados a germinadores tipo B.O.D. regulados para os regimes de temperaturas constantes de 25,30 e $35^{\circ} \mathrm{C}$ e alternada de $20-30{ }^{\circ} \mathrm{C}$, com fotoperíodo de $8 \mathrm{~h}$, utilizandose lâmpadas fluorescentes tipo luz do dia (4 x $20 \mathrm{~W})$. As avaliações foram efetuadas diariamente após a instalação do teste, computando-se o número de plântulas normais, com raiz primária e parte aérea perfeitas, por um período de 25 dias, quando o experimento foi encerrado.

A primeira contagem de germinação foi conduzida conjuntamente com o teste de germinação, onde se computou as sementes germinadas no sexto dia após a semeadura, sendo os resultados expressos em porcentagem.

$O$ índice de velocidade de germinação (IVG) foi determinado a partir das contagens diárias das sementes germinadas, durante 25 dias, empregando-se a fórmula proposta por Maguire (1962), onde

$$
I V G=\frac{G_{1}}{N}+\frac{G_{2}}{N_{2}}+\ldots+\frac{G_{n}}{N_{n}} \text {, sendo: } \mathrm{G}_{1}, \mathrm{G}_{2} \text { e } \mathrm{G}_{\mathrm{n}}=
$$

número de plântulas normais computadas na primeira, na segunda e na última contagem; $\mathrm{N}_{1}, \mathrm{~N}_{2}$ e $\mathrm{N}_{\mathrm{n}}$ = número de dias da semeadura à primeira, segunda e última contagem.

No final do teste de germinação, as plântulas normais de cada repetição foram medidas, da raiz à parte aérea, com o auxílio de uma régua graduada, sendo os resultados expressos em cm.plântula ${ }^{-1}$.

O delineamento experimental foi inteiramente ao acaso, em esquema fatorial $10 \times 4$ (10 tratamentos prégerminativos e 4 temperaturas), com quatro repetições de 25 sementes por tratamento. Os dados não transformados foram submetidos à análise de variância, utilizando-se o teste $\mathrm{F}$ para comparação dos quadrados médios e as médias comparadas pelo teste de Scott - Knott a 5\% de probabilidade.

\section{RESULTADOS E DISCUSSÃO}

Na Tabela 2 estão os dados referentes à porcentagem de germinação de sementes de Apeiba tibourbou, submetidas a diferentes tratamentos pré-germinativos e temperaturas. É possível, inicialmente, confirmar a ocorrência de dormência tegumentar das sementes, uma vez que a porcentagem de germinação daquelas que não passaram por tratamento pré-germinativo foi nula, independentemente da temperatura adotada. Quanto aos tratamentos utilizados constatou-se eficiência do $T_{2}$ (escarificação mecânica com lixa d'água $\mathrm{n}^{\mathrm{0}} 80$, por 5 minutos), juntamente com a temperatura de $30{ }^{\circ} \mathrm{C}$, pois foi a condição que proporcionou o maior percentual de germinação $(87 \%)$. O tratamento $\mathrm{T}_{2}$ provocou fissuras no tegumento, aumentando a permeabilidade, permitindo assim a embebição e o início do processo de germinação.

TABELA 2. Germinação (\%) de sementes de Apeiba tibourbou Aubl. submetidas a diferentes tratamentos prégerminativos e temperaturas.

\begin{tabular}{|c|c|c|c|c|}
\hline \multirow{2}{*}{ Tratamentos } & \multicolumn{4}{|c|}{ Temperaturas $\left({ }^{\circ} \mathrm{C}\right)$} \\
\hline & 25 & 30 & 35 & $20-30$ \\
\hline $\mathrm{T}_{1}$ & $0 \mathrm{eA}$ & OfA & $0 \mathrm{aA}$ & OfA \\
\hline $\mathrm{T}_{2}$ & $74 \mathrm{aB}$ & $87 \mathrm{aA}$ & $0 \mathrm{aC}$ & $74 \mathrm{aB}$ \\
\hline $\mathrm{T}_{3}$ & $51 \mathrm{bB}$ & $70 \mathrm{bA}$ & $0 \mathrm{aD}$ & $38 \mathrm{bC}$ \\
\hline $\mathrm{T}_{4}$ & $39 \mathrm{cB}$ & $51 \mathrm{cA}$ & $0 \mathrm{aD}$ & $30 \mathrm{cC}$ \\
\hline $\mathrm{T}_{5}$ & $0 \mathrm{eC}$ & $28 \mathrm{dA}$ & $0 \mathrm{aC}$ & $9 \mathrm{~dB}$ \\
\hline $\mathrm{T}_{6}$ & $0 \mathrm{eA}$ & OfA & $0 \mathrm{aA}$ & OfA \\
\hline $\mathrm{T}_{7}$ & $0 \mathrm{eA}$ & OfA & $0 \mathrm{aA}$ & OfA \\
\hline $\mathrm{T}_{8}$ & $0 \mathrm{eA}$ & OfA & $0 \mathrm{aA}$ & OfA \\
\hline $\mathrm{T}_{9}$ & $0 \mathrm{eA}$ & $2 \mathrm{fA}$ & $0 \mathrm{aA}$ & OfA \\
\hline $\mathrm{T}_{10}$ & $6 \mathrm{dA}$ & $9 \mathrm{eA}$ & $0 \mathrm{aB}$ & $1 \mathrm{eB}$ \\
\hline
\end{tabular}

$T_{1}$ - Testemunha; $T_{2}$ - Escarificação mecânica com lixa; $T_{3}$ - Escarificação mecânica com lixa + embebição por 12 h; $T_{4}$ - Escarificação mecânica com lixa + embebição por $24 \mathrm{~h} ; \mathrm{T}_{5}$ - Imersão em água a $100^{\circ} \mathrm{C}$, por 15 min.; $\mathrm{T}_{6}, \mathrm{~T}_{7}, \mathrm{~T}_{8}, \mathrm{~T}_{9}$ e $\mathrm{T}_{10}$ - Imersão em ácido sulfúrico por $1,5,10,15$ e 20 min., respectivamente.

Médias seguidas de mesma letra, minúscula na coluna e maiúscula na linha, não diferem entre si, a 5\% de probabilidade pelo teste de Scott - Knott. 
No habitat natural a dormência das sementes é removida por processos que resultem na ruptura ou no enfraquecimento do tegumento, permitindo a passagem de água e gases, dando início ao processo germinativo (Mayer e Poljakoff-Mayber, 1989). Villiers (1975) afirma que a dormência pode ser superada naturalmente por danos mecânicos causados por predação por insetos, decomposição do envoltório seminífero por microrganismos ou, ainda, pela ação do fogo.

Para sementes de Peltophorum dubium (Spreng.) Taub. a escarificação mecânica do lado oposto ao da emissão da radícula foi eficiente para superar a dormência (Piroli et al., 2005). A escarificação manual também foi eficiente para superar a dormência de sementes de Trifolium riograndense Burkart e Desmanthus depressus Humb. (Suñé e Franke, 2006). Para a superação da dormência das sementes de Adenanthera pavonina L. deve-se proporcionar abrasão com lixa no 80 durante 20 segundos (Rodrigues et al., 2009).

O tratamento de escarificação mecânica com lixa d'água $\mathrm{n}^{-} 80$ por 5 minutos, seguidos da embebição em água por $12 \mathrm{~h}\left(\mathrm{~T}_{3}\right)$ associado à temperatura de 30 ${ }^{\circ} \mathrm{C}$ proporcionou um porcentual de germinação de $70 \%$, entretanto quando o tempo de permanência aumentou para $24 \mathrm{~h}\left(\mathrm{~T}_{4}\right)$ foi registrada uma redução significativa na porcentagem de germinação (51\%). A embebição, possivelmente, pode ter sido o fator limitante para a germinação nestas condições devido os danos ocorridos pela embebição por períodos prolongados $(24 \mathrm{~h})$, os quais permitiram que os tecidos se tornassem mais tenros e, portanto, mais susceptíveis ao ataque de fungos. Castro et al. (2004) relataram que as sementes quando colocadas para embeber podem sofrer danos irreversíveis no sistema de membranas, o que leva a lixiviação de conteúdos celulares, afetando negativamente a germinação. A hidratação da semente leva à liberação de solutos para o meio circundante, tais como açúcares, ácidos orgânicos, aminoácidos e vários íons, o que pode estimular o crescimento de patógenos, causando a deterioração das sementes (Bewley e Black, 1994).

A baixa germinação obtida após 15 minutos de imersão em água a $100{ }^{\circ} \mathrm{C}\left(\mathrm{T}_{5}\right)$ indicaram provável ocorrência de algum tipo de dano fisiológico na estrutura interna das sementes, uma vez que foi observada a liberação de exsudados. A alta temperatura possivelmente atingiu o embrião das sementes, causando a morte dos mesmos. Segundo Mayer e Poljakoff-Mayber (1989) a água fervente pode desnaturar as proteínas do tegumento e aumentar a capacidade de absorção de água. Comportamento similar foi registrado em sementes de Cassia excelsa Scharad (Jeller e Perez, 1999).

Embora tenha estimulado o processo de germinação das sementes por meio da protrusão da radícula, a temperatura de $35{ }^{\circ} \mathrm{C}$, independentemente do tratamento pré-germinativo aplicado, inibiu o desenvolvimento subsequente do processo germinativo, impedindo completamente a formação de plântulas normais e favorecendoa deterioraçãoemorte das sementes, constatada pela liberação de exsudados no meio germinativo e pelo desenvolvimento de fungos na superfície das sementes. Fato semelhante ocorreu em sementes de Euterpe edulis M. (Andrade et al., 1999), Brosimum gaudichaudii (Añez et al., 2002) e de Amburana acreana (Ducke) A. C. Sm. (Bello et al., 2008).

A imersão das sementes de $A$. tibourbou em ácido sulfúrico por $1,5,10,15$ e 20 minutos $\left(\mathrm{T}_{6}, \mathrm{~T}_{7}, \mathrm{~T}_{8}, \mathrm{~T}_{9}\right.$ e $\mathrm{T}_{10}$, respectivamente) provocou a morte de todas as sementes. Possivelmente isto ocorreu devido a algum dano fisiológico na estrutura interna das sementes, com comprometimento do embrião. Estes dados discordam dos obtidos por Pacheco e Matos (2009) para a mesma espécie em estudo, uma vez que os autores indicaram a imersão em ácido sulfúrico por 1 minuto. Conforme afirma Dias (2005) mesmo para uma mesma espécie, o período e a intensidade da dormência podem variar em função do genótipo, do ambiente onde a semente foi produzida e de outros fatores, o que pode justificar a diferença de resultados entre estes trabalhos. Smith et al. (2003) mencionam que o grau de dormência entre e dentro de lotes de sementes da mesma espécie varia de acordo com procedência, ano de colheita e de árvores individuais.

Os dados referentes ao vigor, determinado pela primeira contagem de germinação estão na Tabela 3 . À semelhança da percentagem de germinação, o maior percentual de plântulas normais na primeira contagem também foi obtido de sementes oriundas do tratamento $\mathrm{T}_{2}$ (escarificação mecânica com lixa d'água no $\mathrm{n}^{\circ} 80$, por 5 minutos), na temperatura de $30{ }^{\circ} \mathrm{C}$. Para os tratamentos $\mathrm{T}_{3}$ e $\mathrm{T}_{4}$ (escarificação mecânica com lixa + embebição por 12 horas e 24 horas, respectivamente), na temperatura de $30{ }^{\circ} \mathrm{C}$ houve uma redução do vigor, quanto foi aumentado o período de embebição. $\mathrm{Na}$ imersão em água à temperatura ambiente por $24 \mathrm{~h}$ também foi registrado baixos porcentuais de emergência, por ocasião da primeira contagem em sementes de Cassia excelsa Scharad (Jeller e Perez, 1999), Bauhinia divaricata L. 
(Alves et al., 2004) e Merremia aegyptia L. (Pereira et al., 2007). Para sementes de Caesalpinia pucherrima (L.) Sw. os maiores porcentuais de sementes germinadas na primeira contagem foram registrados nos tratamentos de escarificação mecânica seguida ou não de embebição por 12 e 24 h (Oliveira et al., 2010).

TABELA 3. Primeira contagem de germinação de sementes de Apeiba tibourbou Aubl. submetidas a diferentes tratamentos pré-germinativos e temperaturas.

\begin{tabular}{ccccc}
\hline \multirow{2}{*}{ Tratamentos } & \multicolumn{4}{c}{ Temperaturas $\left({ }^{\circ} \mathrm{C}\right)$} \\
\cline { 2 - 5 } & 25 & 30 & 35 & $0 \mathrm{~d}-30$ \\
\hline $\mathrm{T}_{1}$ & $0 \mathrm{dA}$ & $0 \mathrm{dA}$ & $0 \mathrm{aA}$ \\
$\mathrm{T}_{2}$ & $57 \mathrm{aB}$ & $65 \mathrm{aA}$ & $0 \mathrm{aD}$ & $27 \mathrm{aC}$ \\
$\mathrm{T}_{3}$ & $41 \mathrm{bA}$ & $0 \mathrm{aC}$ & $14 \mathrm{bB}$ \\
$\mathrm{T}_{4}$ & $21 \mathrm{cA}$ & $0 \mathrm{aC}$ & $8 \mathrm{cB}$ \\
$\mathrm{T}_{5}$ & $7 \mathrm{cB}$ & $0 \mathrm{dA}$ & $0 \mathrm{aA}$ & $0 \mathrm{dA}$ \\
$\mathrm{T}_{6}$ & $0 \mathrm{dA}$ & $0 \mathrm{dA}$ & $0 \mathrm{aA}$ & $0 \mathrm{dA}$ \\
$\mathrm{T}_{7}$ & $0 \mathrm{dA}$ & $0 \mathrm{dA}$ & $0 \mathrm{aA}$ & $0 \mathrm{dA}$ \\
$\mathrm{T}_{8}$ & $0 \mathrm{dA}$ & $0 \mathrm{dA}$ & $0 \mathrm{aA}$ & $0 \mathrm{dA}$ \\
$\mathrm{T}_{9}$ & $0 \mathrm{dA}$ & $0 \mathrm{dA}$ & $0 \mathrm{aA}$ & $0 \mathrm{dA}$ \\
$\mathrm{T}_{10}$ & $0 \mathrm{dA}$ & $0 \mathrm{dA}$ & $0 \mathrm{aA}$ & $\mathrm{d}$ \\
\hline
\end{tabular}

$\mathrm{T}_{1}$ - Testemunha; $\mathrm{T}_{2}$ - Escarificação mecânica com lixa; $\mathrm{T}_{3}$ - Escarificação mecânica com lixa + embebição por 12 h; $\mathrm{T}_{4}$ - Escarificação mecânica com lixa + embebição por $24 \mathrm{~h} ; \mathrm{T}_{5}$ - Imersão em água a $100^{\circ} \mathrm{C}$, por $15 \mathrm{~min}$.; $\mathrm{T}_{6}, \mathrm{~T}_{7}, \mathrm{~T}_{8}, \mathrm{~T}_{9}$ e $\mathrm{T}_{10}$ - Imersão em ácido sulfúrico por $1,5,10,15$ e 20 min., respectivamente.

Médias seguidas de mesma letra, minúscula na coluna e maiúscula na linha, não diferem entre si, a 5\% de probabilidade pelo teste de Scott - Knott

Conforme relatos de Probert (1992) a temperatura ótima para a germinação de sementes está diretamente associada às características ecológicas da espécie, o que foi comprovado no presente trabalho quando se observa os fatores isolados, em que os maiores valores de germinação e de níveis de vigor (primeira contagem) ocorreram nas temperaturas constantes de 25 e $30{ }^{\circ} \mathrm{C}$; enquanto Pacheco et al. (2007) indicaram como temperaturas adequadas para a germinação de sementes de $A$. tibourbou as de 30 e $35^{\circ} \mathrm{C}$. Estas temperaturas correspondem às que são verificadas nos locais de procedência das sementes, para ambos os experimentos.

O maior índice de velocidade de germinação (IVG) das sementes de $A$. tibourbou foi obtido no tratamento $\mathrm{T}_{2}$ (escarificação mecânica com lixa d'água $\mathrm{n}^{\mathrm{0}} 80$, por 5 minutos) sob temperatura de $30{ }^{\circ} \mathrm{C}$ (Tabela 4). $\mathrm{Na}$ temperatura de $25{ }^{\circ} \mathrm{C}$ os índices de velocidade de germinação foram superiores ao da temperatura de 20$30{ }^{\circ} \mathrm{C}$, independentemente do tratamento aplicado às sementes. Tanto a germinação quanto a velocidade de germinação foi maior na temperatura de $30{ }^{\circ} \mathrm{C}$, o que decorreu, possivelmente, pela embebição mais rápida e, consequentemente, pela aceleração das reações metabólicas durante o processo de germinação. Larcher (2000) mencionou que as temperaturas elevadas aceleram os movimentos das moléculas, tornando mais fracas as ligações químicas que associam os átomos. Desta forma, as camadas de lipídios das biomembranas tornam-se mais fluidas, o que ocasiona um aumento do efluxo de material celular para o meio.

A escarificação com lixa proporcionou os maiores índices de velocidade de emergência de plântulas de Caesalpinia pyramidalis Tul. (Alves et al., 2007). Em relação ao índice de velocidade de germinação de sementes de Apeiba tibourbou, Pacheco et al. (2007) verificaram que os maiores valores foram obtidos quando se utilizaram as temperaturas de 30 e $35^{\circ} \mathrm{C}$, com redução significativa na temperatura constante de $25{ }^{\circ} \mathrm{C}$ e nas alternadas de 20-30 ${ }^{\circ} \mathrm{C}$ e $20-35^{\circ} \mathrm{C}$. Os tratamentos com escarificação mecânica seguida de embebição por 12 e $24 \mathrm{~h}$ proporcionaram maiores índices de velocidade de emergência das plântulas de Caesalpinia pucherrima (L.) Sw. (Oliveira et al., 2010). 
TABELA 4. Índice de velocidade de germinação de sementes de Apeiba tibourbou Aubl. submetidas a diferentes tratamentos pré-germinativos e temperaturas.

\begin{tabular}{ccccc}
\hline \multirow{2}{*}{ Tratamentos } & \multicolumn{4}{c}{ Temperaturas $\left({ }^{\circ} \mathrm{C}\right)$} \\
\cline { 2 - 4 } & 25 & 30 & 35 & $0,00 \mathrm{aA}$ \\
\hline $\mathrm{T}_{1}$ & $0,00 \mathrm{eA}$ & $0,00 \mathrm{eA}$ & $0,00 \mathrm{aD}$ \\
$\mathrm{T}_{2}$ & $1,58 \mathrm{bB}$ & $2,77 \mathrm{aA}$ & $0,00 \mathrm{aD}$ & $1,32 \mathrm{bC}$ \\
$\mathrm{T}_{3}$ & $2,57 \mathrm{aB}$ & $1,31 \mathrm{bA}$ & $0,00 \mathrm{aB}$ & $1,74 \mathrm{a} \mathrm{C}$ \\
$\mathrm{T}_{4}$ & $1,19 \mathrm{cA}$ & $0,72 \mathrm{dA}$ & $0,00 \mathrm{aB}$ & $0,65 \mathrm{dA}$ \\
$\mathrm{T}_{5}$ & $0,00 \mathrm{eB}$ & $0,00 \mathrm{eA}$ & $0,00 \mathrm{aA}$ & $0,00 \mathrm{eA}$ \\
$\mathrm{T}_{6}$ & $0,00 \mathrm{eA}$ & $0,00 \mathrm{eA}$ & $0,00 \mathrm{aA}$ & $0,00 \mathrm{eA}$ \\
$\mathrm{T}_{7}$ & $0,00 \mathrm{eA}$ & $0,00 \mathrm{eA}$ & $0,00 \mathrm{eA}$ \\
$\mathrm{T}_{8}$ & $0,00 \mathrm{eA}$ & $0,00 \mathrm{eA}$ & $0,00 \mathrm{eA}$ \\
$\mathrm{T}_{9}$ & $0,00 \mathrm{eA}$ & $0,69 \mathrm{dA}$ & $0,00 \mathrm{aB}$ & $0,00 \mathrm{eB}$ \\
$\mathrm{T}_{10}$ & $0,67 \mathrm{dA}$ & 0
\end{tabular}

$\mathrm{T}_{1}$ - Testemunha; $\mathrm{T}_{2}$ - Escarificação mecânica com lixa; $\mathrm{T}_{3}$ - Escarificação mecânica com lixa + embebição por 12 h; $\mathrm{T}_{4}$ - Escarificação mecânica com lixa + embebição por $24 \mathrm{~h} ; \mathrm{T}_{5}$ - Imersão em água a $100^{\circ} \mathrm{C}$, por 15 min.; $\mathrm{T}_{6}, \mathrm{~T}_{7}, \mathrm{~T}_{8}, \mathrm{~T}_{9}$ e $\mathrm{T}_{10}$ - Imersão em ácido sulfúrico por $1,5,10,15$ e 20 min., respectivamente.

Médias seguidas de mesma letra, minúscula na coluna e maiúscula na linha, não diferem entre si, a 5\% de probabilidade pelo teste de Scott - Knott.

As sementes submetidas ao tratamento $\mathrm{T}_{2}$ (escarificação mecânica com lixa d'água $\mathrm{n}^{\mathrm{o}} 80$ por 5 minutos) na temperatura de $30{ }^{\circ} \mathrm{C}$ originaram plântulas com maior comprimento (Tabela 5), seguido do tratamento $\mathrm{T}_{3}$ (escarificação mecânica com lixa + embebição por $12 \mathrm{~h}$ ) na temperatura de $25^{\circ} \mathrm{C}$. Sementes de Merremia aegyptia L. submetidas aos tratamentos de escarificação mecânica e imersão em ácido sulfúrico por seis minutos originaram plântulas com maior altura (Pereira et al., 2007).

TABELA 5. Comprimento de plântulas de Apeiba tibourbou Aubl. oriundas de sementes submetidas a diferentes tratamentos pré-germinativos e temperaturas.

\begin{tabular}{ccccc}
\hline \multirow{2}{*}{ Tratamentos } & \multicolumn{4}{c}{ Temperaturas $\left({ }^{\circ} \mathrm{C}\right)$} \\
\cline { 2 - 5 } & 25 & 30 & $0,00 \mathrm{aA}$ & 0,30 \\
\hline $\mathrm{T}_{1}$ & $0,00 \mathrm{dA}$ & $0,00 \mathrm{eA}$ & $0,00 \mathrm{aD}$ & $1,43 \mathrm{aC}$ \\
$\mathrm{T}_{2}$ & $2,29 \mathrm{aB}$ & $3,29 \mathrm{aA}$ & $0,00 \mathrm{aD}$ & $1,28 \mathrm{aC}$ \\
$\mathrm{T}_{3}$ & $2,79 \mathrm{bA}$ & $0,00 \mathrm{aD}$ & $1,04 \mathrm{bC}$ \\
$\mathrm{T}_{4}$ & $2,14 \mathrm{bB}$ & $2,46 \mathrm{cA}$ & $0,00 \mathrm{aC}$ & $0,60 \mathrm{cB}$ \\
$\mathrm{T}_{5}$ & $2,04 \mathrm{bB}$ & $1,87 \mathrm{dA}$ & $0,00 \mathrm{aA}$ & $0,00 \mathrm{dA}$ \\
$\mathrm{T}_{6}$ & $0,00 \mathrm{dC}$ & $0,00 \mathrm{eA}$ & $0,00 \mathrm{aA}$ & $0,00 \mathrm{dA}$ \\
$\mathrm{T}_{7}$ & $0,00 \mathrm{dA}$ & $0,00 \mathrm{eA}$ & $0,00 \mathrm{aA}$ & $0,00 \mathrm{dA}$ \\
$\mathrm{T}_{8}$ & $0,00 \mathrm{dA}$ & $0,00 \mathrm{eA}$ & $0,00 \mathrm{aA}$ & $0,00 \mathrm{dA}$ \\
$\mathrm{T}_{9}$ & $0,00 \mathrm{dA}$ & $0,00 \mathrm{eA}$ & $0,00 \mathrm{aC}$ & $0,00 \mathrm{dC}$ \\
$\mathrm{T}_{10}$ & $0,00 \mathrm{dA}$ & $1,86 \mathrm{dA}$ & $1,56 \mathrm{cB}$ &
\end{tabular}

$\mathrm{T}_{1}$ - Testemunha; $\mathrm{T}_{2}$ - Escarificação mecânica com lixa; $\mathrm{T}_{3}$ - Escarificação mecânica com lixa + embebição por 12 h; $\mathrm{T}_{4}$ - Escarificação mecânica com lixa + embebição por $24 \mathrm{~h} ; \mathrm{T}_{5}$ - Imersão em água a $100^{\circ} \mathrm{C}$, por $15 \mathrm{~min}$.; $\mathrm{T}_{6}, \mathrm{~T}_{7}, \mathrm{~T}_{8}, \mathrm{~T}_{9}$ e $\mathrm{T}_{10}$ - Imersão em ácido sulfúrico por $1,5,10,15$ e 20 min., respectivamente.

Médias seguidas de mesma letra, minúscula na coluna e maiúscula na linha, não diferem entre si, a 5\% de probabilidade pelo teste de Scott - Knott. 
A impermeabilidade do tegumento à água na maioria das vezes é vantajosa, já que permite o prolongamento do tempo de vida das sementes, bem como a sobrevivência da espécie em condições naturais, uma vez que distribui a germinação ao longo do tempo ou permite que a germinação ocorra somente quando as condições forem favoráveis à sobrevivência das plântulas. Por outro lado, a dormência é frequentemente, prejudicial às atividades de viveiro onde se deseja que grandes quantidades de sementes germinem em curto espaço de tempo, permitindo a produção de mudas uniformes (Medeiros Filho et al., 2002). Neste caso, o conhecimento de suas causas é de significativa importância prática, visto que, permite a aplicação de tratamentos apropriados para se obter melhor germinação, como é o caso de espécie $A$. tibourbou.

Quanto à adaptação à temperatura, as sementes de $A$. tibourbou demonstraram certa potencialidade adaptativa, apresentando uma elevada germinabilidade numa faixa de temperatura que se situa entre 25 e $30{ }^{\circ} \mathrm{C}$ constante e 20-30 ${ }^{\circ} \mathrm{C}$ alternada. De acordo com Townsend e Macginnies (1972), essa característica de germinar em diferentes temperaturas pode proporcionar uma alta capacidade de estabelecimento no campo, aumentando sua chance de sobrevivência, em comparação com espécies que apresentam estreitos limites de temperatura para germinar.

\section{CONCLUSÃO}

Para o melhor desempenho germinativo de Apeiba tibourbou Aubl. recomenda-se a escarificação mecânica das sementes com lixa d'água no 80 por 5 minutos e a condução do teste de germinação à temperatura de $30^{\circ} \mathrm{C}$.

\section{REFERÊNCIAS}

ALVES, A.U.; DORNELAS, C.S.M.; BRUNO, R.L.A.; ANDRADE, L.A.; ALVES, E.U. Superação da dormência em sementes de Bauhinia divaricata L. Acta Botanica Brasilica, v.18, n.4, 871-879, 2004.

ALVES, E.U.; BRUNO, R.L.A; OLIVEIRA, A.P.; ALVES, A.U.; ALVES, A.U. Ácido sulfúrico na superação da dormência de unidades de dispersão de juazeiro (Zizyphus joazeiro Mart.). Revista Árvore, v.30, n.2, p.187-195, 2006.

ALVES, E.U.; CARDOSO, E.A.; BRUNO, R.L.A.; ALVES, A.U.; ALVES, A.U.; GALINDO, E.A.; BRAGA JÚNIOR, J.M. Superação da dormência de sementes de
Caesalpinia pyramidalis Tul. Revista Árvore, v.31, n.3, p.405-415, 2007.

ANDRADE, A.C.S.; LOUREIRO, M.B.; SOUZA, A.D.O.; RAMOS, F.N.; CRUZ, A.P.M. Reavaliação do efeito do substrato e da temperatura na germinação de sementes de palmiteiro (Euterpe edulis M.). Revista Árvore, v.23, n.3, p.279-283, 1999.

AÑEZ, L.M.M.; VUADEN, E.R.; OLIVEIRA, S.S.; ALBUQUERQUE, M.C.F.; COELHO, M.F.B. Temperaturas para germinação de sementes de mama cadela (Brosimum gaudichaudii Trec - Moraceae). Revista Agricultura Tropical, v.6, n.1, p.167-176, 2002.

BELLO, E.P.B.C.S.; ALBUQUERQUE, M.C.F.; GUIMARÃES, S.C.; MENDONÇA, E.A.F. Germinação de sementes de Amburana acreana (Ducke) A. C. Sm. submetidas a diferentes condições de temperatura e de estresse hídrico. Revista Brasileira de Sementes, v.30, n.3, p.16-24, 2008.

BEWLEY, J.D.; BLACK, M. Seeds: physiology of development and germination. 2.ed. New York: Plenum Press, 1994. 445p.

CARVALHO, N.M.; NAKAGAWA, J. Sementes: ciência, tecnologia e produção. 4.ed. FUNEP: Jaboticabal, 2000. $588 \mathrm{p}$.

CASTRO, R.D.; BRADFORD, K.J.; HILHOSRT, H.W.M. Embebição e reativação do metabolismo. In: FERREIRA, A.G.; BORGHETI, F. Germinação: do básico ao aplicado. Porto Alegre: Artmed., 2004. p.149-162.

DIAS, D.C.F.S. Dormência em sementes: mecanismo de sobrevivência das espécies. Seed News, v.9, n.4, p.24$28,2005$.

EGLEY, G.H. Influence of the seed envelope and growth regulators upon seed dormancy in witchweed (Stringa lutea Lour.). Annals of Botany, v.36, n.147, p.755-770, 1972.

FONSECA, S.C.L.; PEREZ, S.C.J.G.A. Efeito de sais e da temperatura na germinação de sementes de olho-dedragão (Anadenanthera pavonina L. - Fabaceae). Revista Brasileira de Sementes, v.21, n.2, p.70-77, 1999.

HERMANSEN, L.A DURYEA, M.L.; WEST, S.H.; WHITE, T.L.; MALAVASI, M.M. Pretreatments to overcome seed coat dormancy in Dimorphandra mollis. Seed Science and Technology, v.28, n.1, p.581$595,2000$.

JELLER, H.; PEREZ, S.C.J.G.A. Estudo da superação da dormência e da temperatura em sementes de Cassia excelsa Schrad. Revista Brasileira de Sementes, v.21, n.1, p.32- 
40, 1999.

KHAN, A.A. Seed dormancy: concepts and theories. In: KHAN, A.A. The physiology and biochemistry of seed dormancy and germination. North-Holland Publishing Company, 1977. p.29-50.

LARCHER, W. Ecofisiologia vegetal. Trad. De C.H.B.A. Prado. São Carlos: RIMA, 2000. 531p.

LIMA, D.; GARCIA, L.C. Avaliação de métodos para o teste de germinação em sementes de Acacia mangium Willd. Revista Brasileira de Sementes, v.18, n.2, p.180$185,1996$.

LORENZI, H. Árvores brasileiras: manual de identificação e cultivo de plantas arbóreas nativas do Brasil. Nova Odessa: Plantarum, 2002. v.2. 384p.

MAGUIRE, J.D. Speed of germination aid in selection and evaluation for seedling emergence and vigor. Crop Science, v.2, n.2, p.176-177, 1962.

MARCOS FILHO, J. Fisiologia de sementes de plantas cultivadas. Piracicaba: FEALQ, 2005. 495p.

MAYER, A.M.; POLJAKOFF-MAYBER, A. The germination of seeds. 4.ed. New York: Pergamon Press, 1989. 270p.

McDONALD, M.B.; COPELAND, L.O. Seed production: principles and practices. New Jersey: Chapmam \& Hall, 1997. 749p.

MEDEIROS FILHO, S.; FRANÇA, E. A.; INNECCO, R. Germinação de Sementes de Operculina macrocarpa (L.) Farwel e Operculina alata (Ham.) Urban. Revista Brasileira de Sementes, v. 24, n. 2, p.102-107, 2002.

MELO, J.T.; SILVA, J.A.; TORRES, R.A.A.; SILVEIRA, C.E.S.; CALDAS, L.S. Coleta, propagação e desenvolvimento inicial de espécies do cerrado. In: SANO, S.M.; ALMEIDA, S.P. (Ed.). Cerrado: ambiente e flora. Planaltina: EMBRAPA/CPAC, 1998. p.195-235.

MURDOCH, A.J.; ELLIS, R.H. Dormancy, viability and longevity. In: FENNER, M. (Ed.). Seeds: the ecology of regeneration in plant communities. 2.ed. Wallingford: CABI Publishing, 2000. p.183-214.

OLIVEIRA, L.M.; BRUNO, R.L.A.; GONÇALVES, E.P.; LIMA JÚNIOR, A.R. Tratamentos pré-germinativos em sementes de Caesalpinia pulcherrima (L.) Sw. Leguminosae. Revista Caatinga, v.23, n.1, p.71-76, 2010.

PACHECO, M.V.; MATOS, V.P. Método para superação de dormência tegumentar em sementes de Apeiba tibourbou Aubl. Revista Brasileira de Ciências Agrárias, v.4, n.1, p.62-66, 2009.

PACHECO, M.V.; MATOS, V.P.; FERREIRA, R.L.C.; FELICIANO, A.L.P. Germinação de sementes de Apeiba tibourbou Aubl. em função de diferentes substratos e temperaturas. Scientia Forestalis, n.73, p.19-25, 2007.

PEREIRA, E.W.L.; RIBEIRO, M.C.C.; SOUZA, J.O.; LINHARES, P.C.F.; NUNES, G.H.S. Superação de dormência em sementes de jitirana (Merremia aegyptia L.). Revista Caatinga, v.20, n.2, p.59-62, 2007.

PIÑA-RODRIGUES, F.C.M.; AGUIAR, I.B. Maturação e dispersão de sementes. In: AGUIAR, I.B.; PIÑARODRIGUES, F.C.M.; FIGLIOLIA, M.B. (Org.). Sementes florestais tropicais. Brasília: ABRATES, 1993. p.83-135.

PIROLI, E.L.; CUSTÓDIO, C.C.; ROCHA, M.R.V;. UDENAL, J.L. Germinação de sementes de canafístula Peltophorum dubium (Spreng.) Taub. tratadas para superação da dormência. Colloquium Agrariae, v.1, n.1, p.13-18, 2005.

PROBERT, R.J. The role of temperature in germination ecophysiology. In: FENNER, M. Seeds: the ecology of regeneration in plant communities. Wallingford: CABI, 1992. p.285-325.

RODRIGUES, A.P.D.C.; KOHL, M.C.; PEDRINHO, D.R.; ARIAS, E.R.A.; FAVERO, S. Tratamentos para superar a dormência de sementes de Acacia mangium Willd. Acta Scientiarum Agronomy, v.30, n.2, p.279-283, 2008.

RODRIGUES, A.P.D.C.; OLIVEIRA, A.K.M.; LAURA, V.A.; YAMAMOTO, C.R.; CHERMOUTH, K.S.; FREITAS, M.H. Tratamentos para superação da dormência de sementes de Adenanthera pavonina L. Revista Árvore, v.33, n.4, 2009.

SILVA, K.B.; ALVES, E.U.; BRUNO, R.L.A.; GONÇALVES, E.P.; BRAZ, M.S.S.; VIANA, J.S. Quebra de Dormência em Sementes de Erythryna velutina Willd. Revista Brasileira de Biociências, v.5, supl.2, p.180-182, 2007.

SMIDERLE, O.J.; SOUSA, R.C.P. Dormência em sementes de paricarana (Bowdichia virgilioides Kunth -Fabaceae Papilionoideae). Revista Brasileira de Sementes, v.25, n.1, p.72-75, 2003.

SMITH, M.; WANG, T.B.S.P.; MSANGA, H.P. Chapter 5: Dormancy and Germination. In: Tropical Tree Seed Manual. [s.1]: USDA Forest Service's/Reforestation, Nurseries, \& Genetics Resources, 2003.

SOUSA, A.B.O.; ABUD, H.F.; INNECCO, R. Superação 
de dormência de sementes de Merremia cissoides (Lam.) Hall. F. Revista Caatinga, v.23, n.2, p.1-5, 2010.

SUÑÉ, A.D.; FRANKE, L.B. Superação de dormência e metodologias para testes de germinação em sementes de Trifolium riograndense Burkart e Desmanthus depressus Humb. Revista Brasileira de Sementes, v.28, n.3, p.2936, 2006.
TOWNSEND, C.E.; McGINNIES, W.J. Mechanical scarification of cicer milkvetch (Astragalus cicer L.) seed. Crop and Science, v.12, n.4, p.392-394, 1972.

VILLIERS, T.A. Dormancy and the survival of plants. London: Institute of Biology, 1975. 68p. (Studies in Biology, 57). 